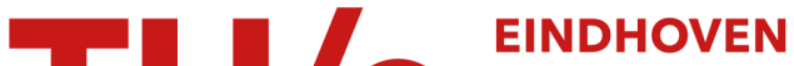

\section{The influence of impurities on the performance of the dielectric barrier discharge}

\section{Citation for published version (APA):}

Martens, T., Bogaerts, A., Brok, W. J. M., \& Dijk, van, J. (2010). The influence of impurities on the performance of the dielectric barrier discharge. Applied Physics Letters, 96(9), 091501-1/3. [091501].

https://doi.org/10.1063/1.3327800

DOI:

$10.1063 / 1.3327800$

Document status and date:

Published: 01/01/2010

\section{Document Version:}

Publisher's PDF, also known as Version of Record (includes final page, issue and volume numbers)

\section{Please check the document version of this publication:}

- A submitted manuscript is the version of the article upon submission and before peer-review. There can be important differences between the submitted version and the official published version of record. People interested in the research are advised to contact the author for the final version of the publication, or visit the $\mathrm{DOI}$ to the publisher's website.

- The final author version and the galley proof are versions of the publication after peer review.

- The final published version features the final layout of the paper including the volume, issue and page numbers.

Link to publication

\section{General rights}

Copyright and moral rights for the publications made accessible in the public portal are retained by the authors and/or other copyright owners and it is a condition of accessing publications that users recognise and abide by the legal requirements associated with these rights.

- Users may download and print one copy of any publication from the public portal for the purpose of private study or research.

- You may not further distribute the material or use it for any profit-making activity or commercial gain

- You may freely distribute the URL identifying the publication in the public portal.

If the publication is distributed under the terms of Article 25fa of the Dutch Copyright Act, indicated by the "Taverne" license above, please follow below link for the End User Agreement:

www.tue.nl/taverne

Take down policy

If you believe that this document breaches copyright please contact us at:

openaccess@tue.nl

providing details and we will investigate your claim. 


\title{
The influence of impurities on the performance of the dielectric barrier discharge
}

\author{
T. Martens, ${ }^{1, a)}$ A. Bogaerts, ${ }^{1}$ W. J. M. Brok, ${ }^{2}$ and J. van Dijk ${ }^{2}$ \\ ${ }^{1}$ Department of Chemistry, University of Antwerp, Universiteitsplein 1, B-2610 Antwerp, Belgium \\ ${ }^{2}$ Department of Applied Physics, Eindhoven University of Technology, 5600 MB Eindhoven, The Netherlands
}

(Received 11 December 2009; accepted 29 January 2010; published online 4 March 2010)

In this letter, we investigate the effect of various levels of nitrogen impurity on the electrical performance of an atmospheric pressure dielectric barrier discharge in helium. We illustrate the different current profiles that are obtained, which exhibit one or more discharge pulses per half cycle and evaluate their performance in ionizing the discharge and dissipating the power. It is shown that flat and broad current profiles perform the best in ionizing the discharge and use the least amount of power per generated charged particle. (c) 2010 American Institute of Physics.

[doi:10.1063/1.3327800]

In this letter, it is demonstrated how different levels of impurity influence the electrical performance of the atmospheric pressure dielectric barrier discharge (DBD). We will show the influence on the time profiles of current and gap voltage and investigate the charged species production in relation with the power consumption. The manifestation of multiple breakdowns per half cycle is also addressed, because it is in close relation with the power consumption. Such additional breakdown pulses can be due to spatially separated breakdowns, as was demonstrated by Mangolini $e t$ al., ${ }^{1}$ or can be due to temporally separated breakdowns, as was demonstrated by Shin et al. ${ }^{2}$ The investigation in the present letter concerns only the temporally separated breakdowns. Based on these studies we can obtain a clear understanding of the governing mechanisms in the discharge.

We use a two-dimensional fluid model, which is part of the Plasimo modeling framework. ${ }^{3}$ The model is based on the continuity equations for mass, momentum and electron energy, which are numerically solved coupled to the Poisson equation for the electric field. More details on the model can be found elsewhere. ${ }^{4}$

The discharge gas is assumed to be atmospheric pressure helium with various nitrogen impurities ranging from zero over a few parts per million to $5 \%$. It is described using nine different species and 18 different chemical reactions which have previously been reported. ${ }^{5}$

The experimental setup under study is exactly the same as the one used by Mangolini et al. ${ }^{6}$ It is a dielectric barrier discharge with both electrodes covered with an alumina dielectric $\left(\epsilon_{r}=9\right)$ of $1 \mathrm{~mm}$ thickness. The spacing between the dielectric surfaces is $5 \mathrm{~mm}$ and on the top electrode a sinusoidal voltage is applied while the bottom electrode is grounded.

In order to first validate our model an electric potential is applied on the powered electrode with a frequency of $10 \mathrm{kHz}$ and an amplitude of $2 \mathrm{kV}$ which is exactly the same as used by Mangolini et al. ${ }^{6}$ In order to stay consistent with their research we used an impurity of $100 \mathrm{ppm}$ of $\mathrm{N}_{2}$, as they estimated from their setup analysis. In Fig. 1 our calculated profiles for current, gap voltage and applied voltage are illustrated together with the experimental results of Mangolini.

\footnotetext{
${ }^{\text {a) }}$ Author to whom correspondence should be addressed. Electronic mail: tom.martens@ua.ac.be.
}

Very good agreement is obtained in the manifestation of a single narrow current peak with an amplitude of several $\mathrm{mA} / \mathrm{cm}^{2}$ every half period when the gap voltage reaches exactly the same value of $1.5 \mathrm{kV}$, as was also obtained by Mangolini. ${ }^{6}$

All the following results are obtained by applying a potential with a frequency of $10 \mathrm{kHz}$ on the powered electrode and an increased voltage amplitude of $2.6 \mathrm{kV}$. These conditions allow us to obtain periodic breakdown behavior for every impurity level under study.

In order to demonstrate how the impurities influence the general electrical characteristics of the discharge, the calculated current density and the gap and applied voltage profiles are plotted in Fig. 2 for a pure He discharge, a He discharge containing $8,100,1000,3850$, and $4000 \mathrm{ppm}$ of $\mathrm{N}_{2}$ impurity. Figure 2 illustrates that for a pure He discharge each half period one narrow current peak with an amplitude of about $2.5 \mathrm{~mA} / \mathrm{cm}^{2}$ is obtained. Increasing the $\mathrm{N}_{2}$ content with a few parts per million leads to current pulses which are lower in amplitude, but last longer in time, so that the transferred charge remains about the same. This trend continues up to an impurity level of $8 \mathrm{ppm}$, where current pulses of only $0.6 \mathrm{~mA} / \mathrm{cm}^{2}$ occur (see Fig. 2). A further increase in the $\mathrm{N}_{2}$

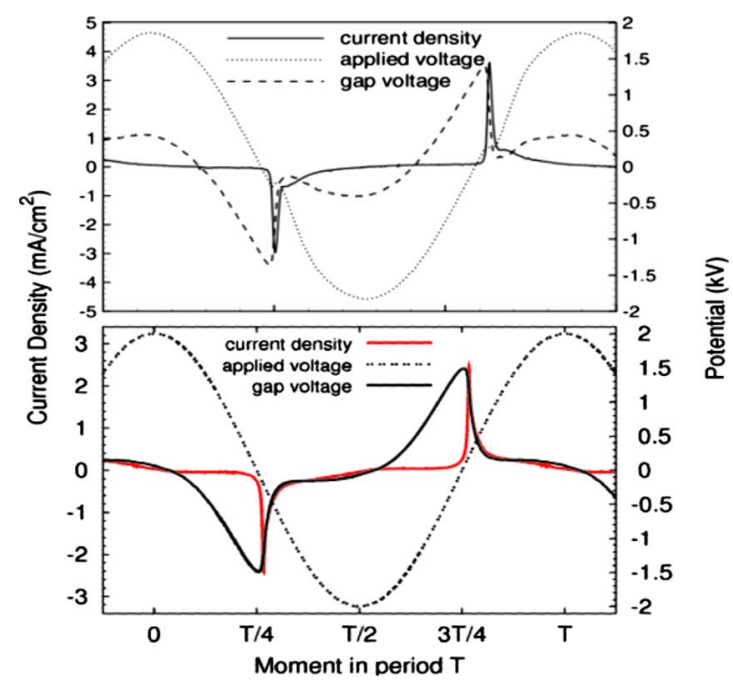

FIG. 1. (Color online) Top frame: Experimental results for the discharge current density, gap voltage, and applied voltage as a function of time obtained by Mangolini et al. (Ref. 6) Bottom frame: Our calculated results using the same conditions with $100 \mathrm{ppm}$ of $\mathrm{N}_{2}$. 


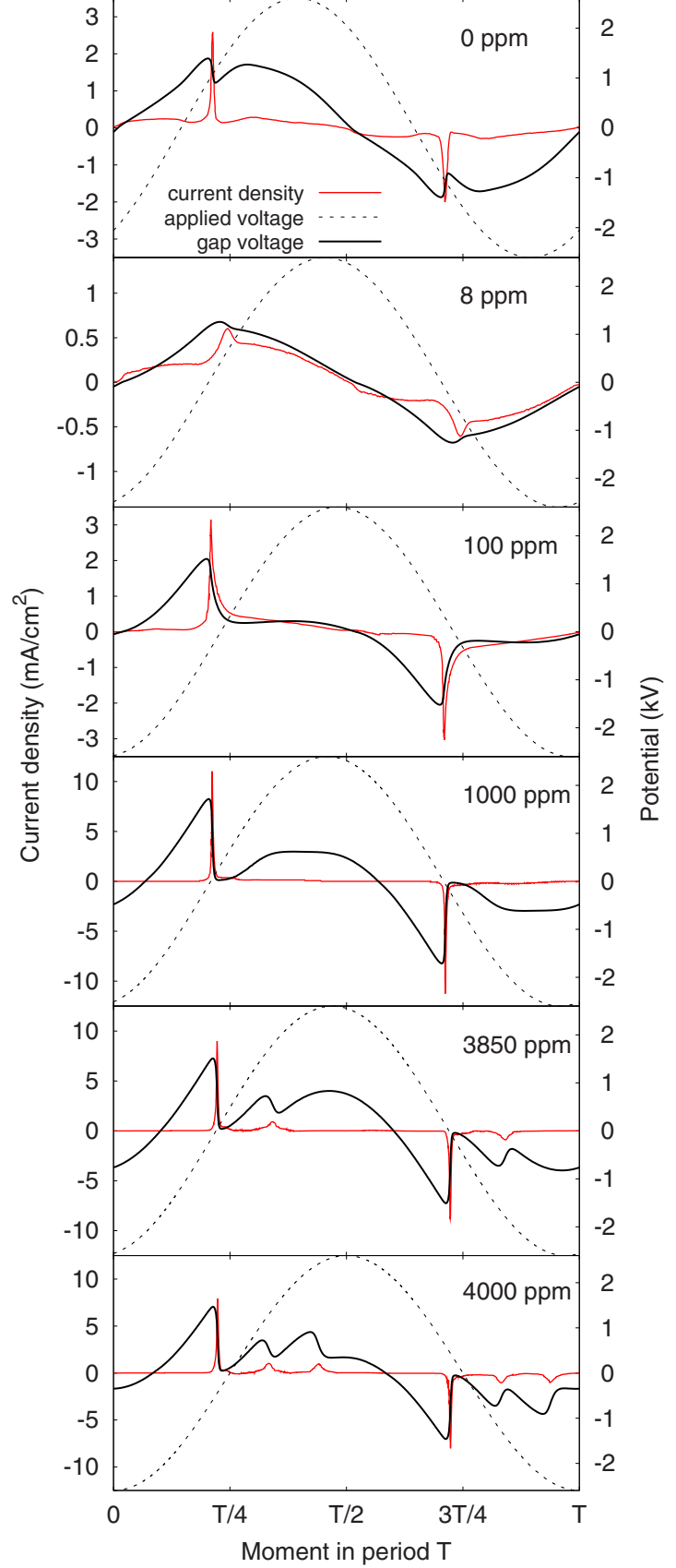

FIG. 2. (Color online) Calculated results for the discharge current density and gap voltage as a function of time, shown together with the applied voltage. Each frame corresponds with a different level of impurity.

content in the discharge causes the current amplitude to increase and the peak width to decrease again, which can be seen in Fig. 2, where the profiles at 100 and 1000 ppm show current amplitudes of 3 and $11 \mathrm{~mA} / \mathrm{cm}^{2}$, respectively. Further increasing the $\mathrm{N}_{2}$ content leads to multiple breakdown behavior. Indeed the additional $\mathrm{N}_{2}$ in the discharge stimulates Penning ionization, which facilitates volume ionization and hence, multiple breakdowns can occur with the same applied voltage. ${ }^{7}$ Figure 2 illustrates a second breakdown at 3850 and for 4000 ppm of $\mathrm{N}_{2}$ also a third breakdown occurs.

These impurities also affect the performance of the discharge. Figure 3 illustrates the time and space averaged electron densities, dissipated powers and the ratios of the electron density to the dissipated power as a function of $\mathrm{N}_{2}$ content. All values are normalized to their highest value. For the electron density this value is $6.4 \times 10^{16} \mathrm{~m}^{-3}$, for the

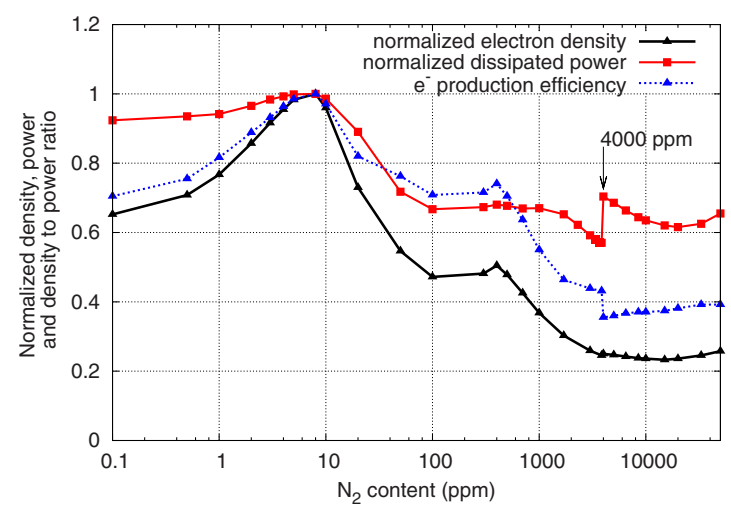

FIG. 3. (Color online) Normalized calculated electron density, dissipated power, and $\mathrm{e}^{-}$production efficiency as a function of $\mathrm{N}_{2}$ content

dissipated power $0.66 \mathrm{~W} \mathrm{~cm}^{-3}$ and their ratio is 9.7 $\times 10^{10} \mathrm{~W}^{-1}$. The degree of ionization is very often a good indication of how active a plasma can be in, for example, dissociating molecules for plasma chemistry purposes. In the present description the electrons are the only negatively charged species. Therefore, their density is a direct measure for the degree of ionization. Figure 3 demonstrates that at a concentration of $8 \mathrm{ppm}$ of $\mathrm{N}_{2}$ in $\mathrm{He}$ the electron density is maximal and by increasing the $\mathrm{N}_{2}$ concentration the electron density and therefore also the degree of ionization decrease. As a consequence, a high purity plasma will have a higher degree of ionization, although the calculated amplitude of the current density is lower (see Fig. 2). This is because the electron density value integrated in time is higher. Indeed at low levels of $\mathrm{N}_{2}$ there is much more continuous generation of charged particles during one period of applied voltage than with high levels of $\mathrm{N}_{2}$. This is reflected in the peak width of the current profiles in Fig. 2 and will be clarified later.

Figure 2 illustrates that increasing the $\mathrm{N}_{2}$ content in the discharge can make the discharge pulse stronger or weaker and can make it last longer or shorter. This behavior affects the power consumption of the discharge, which is determined by the volume integral $\int_{v o l} \bar{J} \cdot \bar{E} \mathrm{~d} V$, where $\overline{\mathrm{J}}$ is the current density and $\overline{\mathrm{E}}$ the electric field calculated using Poisson's law $\bar{\nabla} \cdot(\epsilon \bar{E})=\rho$. Figure 3 illustrates that also the dissipated power is maximal at a $\mathrm{N}_{2}$ content of $8 \mathrm{ppm}$. For higher levels of $\mathrm{N}_{2}$ first the dissipated power drops and for levels of $100 \mathrm{ppm}$ and higher it remains more or less constant, except for an anomaly at $3850 \mathrm{ppm}$. The dissipated power decreases more steeply between 1700 and $3850 \mathrm{ppm}$, whereafter it jumps sharply to a much higher value at 4000 ppm. The reason for this will be discussed below.

The ratio of the electron density to the dissipated power provides for an indication whether a lot of energy is needed to obtain a certain degree of ionization. This ratio is illustrated in Fig. 3 and it also shows a very clear maximum at 8 $\mathrm{ppm}$. For higher levels of $\mathrm{N}_{2}$ the ratio keeps decreasing, except for a very small bump at $400 \mathrm{ppm}$. After this the ratio decreases faster and has a very sharp drop at $3850 \mathrm{ppm}$, due to the steep jump of the dissipated power, which leads to the lowest density to power ratio. This shows that the discharge with the highest degree of ionization, composed of $8 \mathrm{ppm}$ of $\mathrm{N}_{2}$ in $\mathrm{He}$, also has the highest ratio of electron density to dissipated power and hence, is most efficiently dissipating this power to generate electrons. 


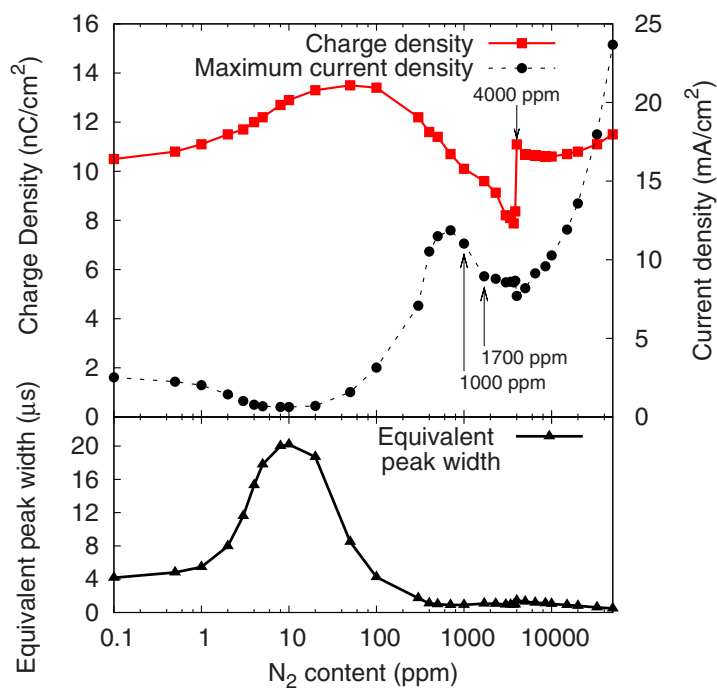

FIG. 4. (Color online) Top frame: Charge density transferred during the positive part of the current pulse and the maximum value of the discharge current as a function of the $\mathrm{N}_{2}$ content. Bottom frame: Equivalent peak width determined by dividing the integrated positive part of the current pulse with the maximum value of the discharge current.

In order to obtain additional information on which types of profiles are responsible for the minima and maxima in electron density, dissipated power and density to power ratio plotted in Fig. 3, the maximum value of the current density and its integrated value during the positive half of a period, which provides for the charge density on the electrode, are plotted in the top frame of Fig. 4. In the bottom frame the ratio of this integrated value to the maximum current density is shown. We call this value the "equivalent peak width," because it provides for the peak width in case the peak would have a rectangular shape. This is a good approximation when the current pulse is very narrow, as for 0,100 , and $1000 \mathrm{ppm}$ of $\mathrm{N}_{2}$ in Fig. 2. However, it is merely an indicative value for flat and broad profiles such as at $8 \mathrm{ppm}$ of $\mathrm{N}_{2}$, and for profiles with secondary and tertiary discharge pulse, as can be seen for 3850 and 4000 ppm in Fig. 2. For these situations, however, the obtained value still provides valuable information whether the current profile is flat and broad or sharp and narrow.

Figure 4 demonstrates that with $8 \mathrm{ppm}$ of $\mathrm{N}_{2}$, which exhibited the highest ionization and efficiency in Fig. 3, the profile with the lowest maximum current density and the second largest peak width is obtained. This means that a very flat and broad current profile is associated with the highest degree of ionization and it is most efficiently using the dissipated power to ionize the gas. The performance of the typical narrow current pulses obtained with $\mathrm{N}_{2}$ levels ranging from 100 to $1000 \mathrm{ppm}$, on the other hand, is only mediocre, as can be seen in Fig. 3 .

The reason for the manifestation of narrow and broad current profiles lies not in spatial variations but in the time resolution of the ionization processes. Increasing the $\mathrm{N}_{2}$ content in the discharge promotes the $\mathrm{N}_{2}$ depending ionization pathways. Detailed reaction analysis has shown that at very low impurity levels $(<3 \mathrm{ppm})$ most electrons are produced by the Penning ionization of $\mathrm{He}_{2}^{*}$ by $\mathrm{He}_{2}^{*}$ and by the electron induced ionization of $\mathrm{He}$, while at $3 \mathrm{ppm}$ of $\mathrm{N}_{2}$ impurity the Penning ionization of $\mathrm{N}_{2}$ by $\mathrm{He}_{2}^{*}$ becomes the most important electron production reaction. Because the $\mathrm{He}_{2}^{*}$ densities are independent of the electron energy, they do not change much in time. As a consequence, also the time variation of this Penning ionization remains small. This provides for a constant supply of charged species, which causes broad current profiles.

A further increase in $\mathrm{N}_{2}$ makes Penning ionization of $\mathrm{N}_{2}$ by $\mathrm{He}_{m}^{*}$ already at $10 \mathrm{ppm}$ the most important ionization reaction. This reaction attains a narrow maximum right after breakdown, because the $\mathrm{He}_{m}^{*}$ density is directly related to the electron density and energy. A further increase in $\mathrm{N}_{2}$ also makes $\mathrm{N}_{4}^{+}$the most important positive species in the discharge. ${ }^{5}$ As a consequence, the fast recombination of the electrons with $\mathrm{N}_{4}^{+}$becomes very important. This process is most efficient when electron energy is low, ${ }^{5}$ which occurs when gap voltage is low. These last two processes cause that the ionization level becomes very high right after breakdown and that the electrons are quickly lost again due to recombination with $\mathrm{N}_{4}^{+}$, which makes the current peaks narrow again.

The above processes are responsible for the transition region from about 2 to $50 \mathrm{ppm}$ (see Fig. 4) in which the current profiles change from narrow to broad and back to narrow and where the $\mathrm{N}_{2}$ depending ionization rates become gradually more important than the rates depending solely on He.

The discontinuity in the dissipated power at $4000 \mathrm{ppm}$, as shown in Fig. 3, originates from a sudden change in the transferred charge on the electrode, which is displayed in Fig. 4. The discontinuity originates from the formation of a tertiary breakdown pulse. Indeed, it was demonstrated in Fig. 2 that for $3850 \mathrm{ppm}$ of $\mathrm{N}_{2}$ there are two current pulses, while for $4000 \mathrm{ppm}$ also a third pulse appeared. Analysis of the reaction chemistry and current profiles tells us that this tertiary discharge pulse is formed out of a tail of the previous current peak, which gradually transforms into a new current peak. Indeed, as the $\mathrm{N}_{2}$ content in the discharge increases, also the $\mathrm{N}_{4}^{+}$concentration rises and consequently, the recombination of electrons with $\mathrm{N}_{4}^{+}$right after the first current pulse eliminates the charge carriers faster and faster. The elimination of charged species allows the gap voltage to increase again, because they are not able to compensate the governing electric field anymore by charging the dielectrics. This process is also responsible for the transition from one to two peaks between 1000 and $1700 \mathrm{ppm}$, but because the $\mathrm{N}_{2}$ content and, hence, the $\mathrm{N}_{4}^{+}$ion density are both still lower, the process is not yet so dominant. Hence, the transition occurs now gradually, explaining why for the formation of the secondary pulse no jump is observed in Figs. 3 and 4.

${ }^{1}$ L. Mangolini, K. Orlov, U. Kortshagen, J. Heberlein, and U. Kogelschatz, Appl. Phys. Lett. 80, 1722 (2002).

${ }^{2}$ J. Shin and L. Raja, J. Appl. Phys. 94, 7408 (2003).

${ }^{3}$ J. van Dijk, K. Peerenboom, M. Jimenez, D. Mihailova, and J. van der Mullen, J. Phys. D: Appl. Phys. 42, 194012 (2009).

${ }^{4}$ G. Hagelaar, Ph.D. thesis, Technical University of Eindhoven, 2000.

${ }^{5}$ T. Martens, A. Bogaerts, W. J. M. Brok, and J. v Dijk, Appl. Phys. Lett. 92, 041504 (2008).

${ }^{6}$ L. Mangolini, C. Anderson, J. Heberlein, and U. Kortshagen, J. Phys. D: Appl. Phys. 37, 1021 (2004).

${ }^{7}$ I. Radu, R. Bartnikas, and M. R. Wertheimer, IEEE Trans. Plasma Sci. 31, 1363 (2003). 